\title{
Prevalence and Risk Factors of E-cigarette Users in Thai College Student
}

\author{
Chatuthanai Savigamin ${ }^{1}$, Jedsadakorn Jitwimungsanon ${ }^{1}$, Thanapoom Rattananupong ${ }^{2}$, \\ Chanchai Sittipunt ${ }^{3}$, Thitiwat Sriprasart ${ }^{3,4, *}$ \\ ${ }^{1}$ Faculty of Medicine, Chulalongkorn University, Bangkok, Thailand \\ ${ }^{2}$ Department of Preventive and Social Medicine, Faculty of Medicine, Chulalongkorn University, Bangkok, Thailand \\ ${ }^{3}$ Division of Pulmonary and Critical Care Medicine, Department of Medicine, Faculty of Medicine, Chulalongkorn University, Bangkok, \\ Thailand \\ ${ }^{4}$ Division of Pulmonary and Critical Care Medicine, Department of Medicine, King Chulalongkorn Memorial Hospital, Thai Red Cross \\ Society, Bangkok, Thailand
}

\section{Email address:}

chatuthanai.s@gmail.com (C. Savigamin),flukejedsada@hotmail.com (J. Jitwimungsanon), athanapoom@gmail.co (T. Rattananupong), sittipunt@gmail.com (C. Sittipunt), thitiwatsr@yahoo.com (T. Sriprasart)

${ }^{*}$ Corresponding author

\section{To cite this article:}

Chatuthanai Savigamin, Jedsadakorn Jitwimungsanon, Thanapoom Rattananupong, Chanchai Sittipunt, Thitiwat Sriprasart. Prevalence and Risk Factors of E-cigarette Users in Thai College Student. Clinical Medicine Research. Vol. 10, No. 2, 2021, pp. 47-52.

doi: $10.11648 /$ j.cmr.20211002.13

Received: March 19, 2021; Accepted: April 1, 2021; Published: April 12, 2021

\begin{abstract}
Background: Electronic cigarette (E-cigarette) has gained popularity internationally. It was claimed to be a novel way of smoking cessation. Previous reports regarding E-cigarette in Thai college student were limited. We investigated the prevalence, characteristics, and risk factors of e-cigarette smoking in Thai college students. Method: This is a descriptive cross-sectional study of prevalence, characteristics and risk factors of E-cigarette user in college students in Bangkok in January 2018. We used simple random sampling method and self-interviewed anonymous online questionnaire. The primary outcome was the prevalence of E-cigarette user. Secondary outcome were the characteristics and risk factors of E-cigarette users. Result: There were 1302 college students which 535 students $(41.1 \%)$ were male, and 767 students $(58.9 \%)$ were female. 289 students $(22.2 \%)$ were E-cigarette users. 223 students had history of both cigarette and E-cigarette used. History of cigarette used in 30 days, history of cigarette used not in 30 days, water pipe user, marijuana user and male were risk factors of using E-cigarette by adjusted odds ratio 24.59 (95\% CI 13.31- 45.43), 15.12 (95\% CI 9.06 - 25.23), 10.08 (95\% CI 6.38 15.92), 11.59 (95\% CI 4.61 - 29.14), 1.90 (95\% CI 1.25 - 2.90) respectively. Studying in non-health faculties was the risk factor for E-cigarette used with adjusted odds ratio of 2.07 (95\% CI 1.05 - 4.10). Conclusion: Prevalence of E-cigarette users in Thai college student was high. Risk factors included male, history of cigarette smoking, marijuana use, water pipe and studying in non-health associated faculty. Effective control and education are needed.
\end{abstract}

Keywords: E-cigarette, Prevalence, Risk Factors, College Student

\section{Introduction}

Electronic cigarette (E-cigarette) is a device that use heat energy to vaporize nicotine and flavor. It was advertised to be less dangerous than cigarette and a novel method of smoking cessation. Appearance and specification of E- cigarette are varied depending on physical property of the device such as disposable e-cigarette, rechargeable e-cigarette, tank style and pen style [1].
Prevalence of E-cigarette user has been increased around the world. In United States, the prevalence was increased from 3.3\% in 2010 to $8.5 \%$ in 2013 [2]. In Europe, the prevalence of ever used e-cigarette was increased from $7.2 \%$ in 2012 to $11.6 \%$ in 2014 [3]. In Asia, the study of the prevalence of e-cigarette user in Taiwan was $6.5 \%$ [4]. Prevalence of E-cigarette user ranges from $4.9 \%$ to $74.9 \%$ [5-7] around the world.

The consequence of E-cigarette used has been reported 
worldwide. Recently, E-cigarette was reported to be associated with pulmonary illness which could result from severe respiratory symptom to death [8]. Moreover, carcinogenicity in lung and bladder was also reported but limited to the animal study [9]. Psychologically, E-cigarette users were found more likely to have problem in attention deficit, low self-esteem, post-traumatic stress disorder, gambling disorder, anxiety, and impulsivity. [10]

College students have been known to be targeted population of cigarette smoking. [11] In Thailand, E-cigarette is considered illegal. The prevalence of E-cigarette user Thailand was $3.3 \%$ in young adult aged 13-15 years [12]. Another reports found that the highest proportion of E-cigarette users was adult aged 19-24 years and work as business employee respectively [13, 14]. There was no report regarding the prevalence and risk factors of E-cigarette user in college students in Thailand. Therefore, we reported the prevalence of E-cigarette user and risk factors in Thai college students.

\section{Method}

\subsection{Study Design and Population}

This study was a descriptive cross-sectional study of prevalence and characteristics of electronic-cigarette user and non-user in college student in single university in Bangkok, Thailand. We recruited students from 19 faculties that range from $1^{\text {st }}$ year to $6^{\text {th }}$ year in the campus in January 2018. The youngest age was 17 years old. We used simple random sampling method and approached student by face-to-face or using LINE application (Naver, Japan). Then, students were provided a $\mathrm{QR}$ code of self-interviewed anonymous online questionnaire which created specifically for this study. The questionnaire never been published elsewhere.

\subsection{Ethics}

The ethical committee approval was determined unnecessary by the authors because this study was an anonymous observational study with minimal risk to subject. This study met the criteria of Exemption from International Ethical Guidelines for health-related research Involving Human 2016 [15]. The participant was informed about objectives, confidentiality, study project and giving the consent. Then, the participant did the online questionnaires via the link. The data was kept anonymous without name or contact of the participants.

\subsection{Variable}

Our primary outcome was the prevalence of E-cigarette users in college students. Secondary outcome of this study was the characteristics of the E-cigarette user and risk factor of using E-cigarette.

\subsection{Sample Size Measurement}

In previous study, there was $23 \%$ of population that used E-cigarette. With 95\% confidentiality, we determined accepted error rate of $2 \%$ and non-response rate of $10 \%$. The calculated sample size was 1890 participants.

\subsection{Data Measuring}

Characteristic of E-cigarette used and the demographic including biological sex, faculty, academic performance determined by Grade Point Average (GPA), income, frequency of smoking (pack per week) and another illicit drug use were included in questionnaire. GPA were categorized into $<3,3-3.50,>3.50$. The higher GPA indicated the better academic performance. We defined past user as the person who stopped E-cigarette more than 30 days. The current user was defined as the person who currently use Ecigarette or stopped using E-cigarette less than 30 days. Both current users and past users were called E-cigarette users. We use same definition as above in cigarette to define smoker and past smoker.

We used IBM SPSS statistical 22 (IBM Corp. Released 2013. IBM SPSS Statistics for Windows, Version 22.0. Armonk, NY: IBM Corp) to analyze demographic data and express data in percent.

We used multiple logistic regression with adjusted covariates and reported in Odds ratio (95\% confidence interval) in order to determine the odds between E-cigarette and other factors. Confounders in calculation included gender, history of smoking cigarette, marihuana use, water pipe use, other illicit drug use and studying in health faculties.

\subsection{Biases}

We tried to avoid inclusive bias by assigning our team member to 10 areas in the university to recruit students. This assignment will cover all faculties in the university. Procedural bias was reduced by giving unlimited time to answer questionnaire. Anonymous questions were used to avoid measurement bias in stigma question.

\section{Result}

There were 1302 college students which shows $68.9 \%$ response rate. 535 students $(41.1 \%)$ were male and 767 students $(58.9 \%)$ were female. The demographic data was reported in Table 1.

Table 1. Demographic data of included college student $n=1302$.

\begin{tabular}{ll}
\hline Variables & $\begin{array}{l}\text { Number of Students } \\
\text { (Percent) }\end{array}$ \\
\hline Gender & $535(41.1 \%)$ \\
Male & $767(58.9 \%)$ \\
Female & \\
Faculties & $198(15.1 \%)$ \\
Faculty of Engineering & $163(12.4)$ \\
Faculty of Science & $122(9.3 \%)$ \\
Faculty of Commerce and Accountancy & $90(6.9 \%)$ \\
Faculty of Education & $87(6.6 \%)$ \\
Faculty of Medicine & $78(5.9 \%)$ \\
Faculty of Law & $564(43.7 \%)$ \\
Others & \\
Academic performance & \\
\hline
\end{tabular}




\begin{tabular}{ll}
\hline Variables & $\begin{array}{l}\text { Number of Students } \\
\text { (Percent) }\end{array}$ \\
\hline$<3.00$ & $506(38.9 \%)$ \\
$3.01-3.50$ & $490(37.6 \%)$ \\
$3.51-4.00$ & $306(23.5 \%)$ \\
Monthly income & $207(15.8 \%)$ \\
$0-5,000$ & $592(45.1 \%)$ \\
$5,001-10,000$ & $318(24.2 \%)$ \\
$10,000-15,000$ & $185(14.9 \%)$ \\
$>15,000$ & \\
History of using Cigarette & $1021(78.4 \%)$ \\
Never & $141(10.8 \%)$ \\
Smoking in the past 30 days & $140(10.8 \%)$ \\
Smoked but not in the past 30 days & \\
Frequency of Smoking cigarette (pack/week) & $1088(83.5 \%)$ \\
Never & $146(11.2 \%)$ \\
$0-1$ & $39(3.0 \%)$ \\
$1-2$ & $14(1.1 \%)$ \\
$3-4$ & $15(1.2 \%)$ \\
$>4$ & \\
History of E-cigarette smoking & $1013(77.8 \%)$ \\
Never & $109(8.4 \%)$ \\
Smoking in the past 30 days & $180(13.8 \%)$ \\
\hline Smoked but not in the past 30 days & \\
\hline
\end{tabular}

There were 289 (22.2\%) E-cigarette users. In this group, 182 students (63\%) and 107 students (37\%) were male and female, respectively. 109 students $(8.4 \%)$ were current users, and 180 students $(13.8 \%)$ were past users. The highest incidence of Ecigarette user was found in faculty of engineering with $42.5 \%$ of all students in the faculty. Among 309 illicit drug users, 218 students use E-cigarette (70.6\%). The incidence of E-cigarette in marihuana users and water pipes users were $35(77.7 \%)$ and $172(71.1 \%)$ respectively (Table 2$)$

Table 2. Combined E-cigarette with another illicit drug use.

\begin{tabular}{llll}
\hline \multirow{2}{*}{$\begin{array}{l}\text { History of illicit drug } \\
\text { use }\end{array}$} & E-cigarette use & \multirow{2}{*}{ Total } \\
\cline { 2 - 3 } & Yes & No & \\
\hline Marijuana & $35(77.8 \%)$ & $10(22.2 \%)$ & 45 \\
Water pipes & $172(71.1 \%)$ & $70(28.9 \%)$ & 242 \\
ETC & $11(27.3 \%)$ & $11(72.7 \%)$ & 22 \\
Total number & 218 & 91 & 309 \\
\hline
\end{tabular}

223 students with history of cigarette smoking had history of E-cigarette smoking. 61 students of 223 were currently dual smokers. The number of E-cigarette users in GPA < $3.00,3.01-3.50,3.51-4.00$ were 146, 106, 37 students, respectively. $180(62.3 \%)$ students borrowed E-cigarette from friends and $58(20.1 \%)$ students bought online (Figure 1).

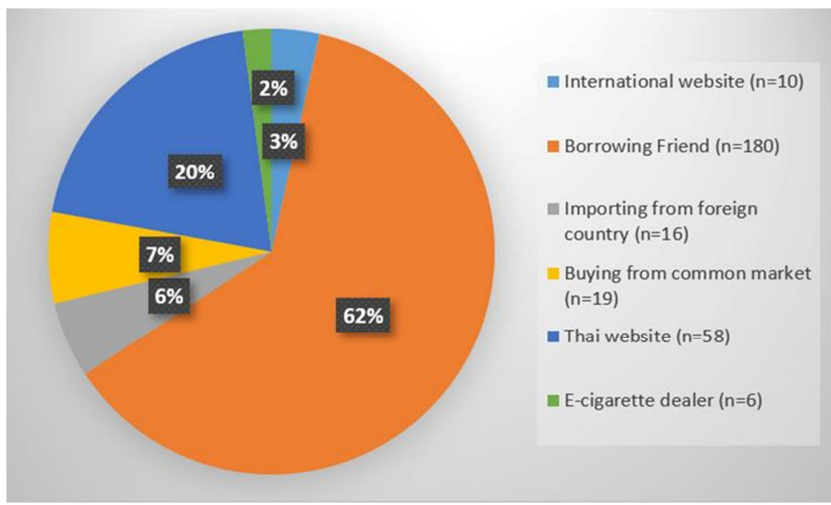

Figure 1. Source of E-cigarette $(n=289)$.

Most college students received E-cigarette information from friends (32.8\%) and television (22.8\%) (Figure 2).

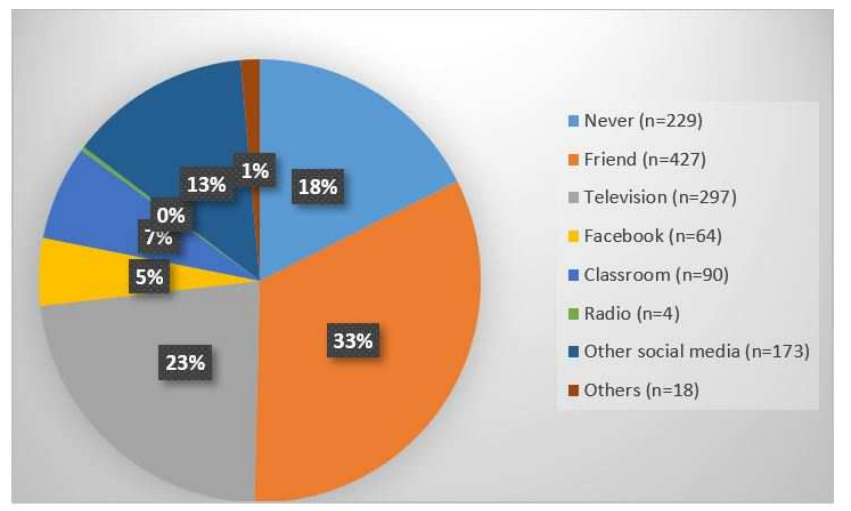

Figure 2. Sources of E-cigarette information $(n=1302)$.

History of cigarette smoking in 30 days, cigarette smoking not in 30 days, water pipe users, marijuana users and male are risk factors of using E-cigarette by adjusted odds ratio 24.59 (95\% CI 13.31- 45.43), 15.12 (95\% CI 9.06 - 25.23), 10.08 (95\% CI $6.38-$ 15.92), 11.59 (95\% CI 4.61 - 29.14), 1.90 (95\% CI 1.25 - 2.90) respectively. College students who used cigarette, water pipe, marijuana were at risk of E-cigarette using by 25, 10, 12 times higher than college students with none of these factors. The risk factor of using E-cigarette was also studying in non-medicine and non-allied health faculty (All faculties except Medicine, Veterinary science, Dentistry, Pharmaceutical science, and Allied health science) with adjusted odds ratio of 2.07 (95\% CI $1.05-$ 4.10) (Table 3).

Table 3. Risk factors of characteristics to E-cigarette using.

\begin{tabular}{|c|c|c|c|c|c|c|}
\hline Factors & $\begin{array}{l}\text { E-cigarette use } \\
\text { Yes n }(\%)\end{array}$ & $\begin{array}{l}\text { E-cigarette use } \\
\text { No n }(\%)\end{array}$ & $\begin{array}{l}\text { Crude odds } \\
\text { ratio }\end{array}$ & $(95 \% \mathrm{CI})$ & $\begin{array}{l}\text { Adjusted odds } \\
\text { ratio }\end{array}$ & $(95 \% \mathrm{CI})$ \\
\hline \multicolumn{7}{|l|}{ Gender } \\
\hline Male & $182(34 \%)$ & $353(66 \%)$ & 3.18 & $2.42-4.17$ & 1.90 & $1.25-2.90$ \\
\hline Female & $107(14 \%)$ & $660(86 \%)$ & 1.00 & reference & 1.00 & reference \\
\hline \multicolumn{7}{|l|}{ History of smoking cigarette } \\
\hline - Smoking in the past 30 days & $20(14.1 \%)$ & $121(85.9 \%)$ & 87.54 & $51.28-149.45$ & 24.59 & $13.31-45.43$ \\
\hline - Did not smoke in the past 30 days & $38(27.2 \%)$ & $102(72.8 \%)$ & 38.84 & $24.81-60.81$ & 15.12 & $9.06-25.23$ \\
\hline - Never smoke cigarette & $66(6.5 \%)$ & $955(93.5 \%)$ & 1.00 & reference & 1.00 & reference \\
\hline Marihuana use & $35(77.8 \%)$ & $10(22.2 \%)$ & 14.04 & $6.86-28.75$ & 11.59 & $4.61-29.14$ \\
\hline Water pipe use & $172(71.1 \%)$ & $70(29.9 \%)$ & 20.70 & $14.73-29.09$ & 10.08 & $6.38-15.92$ \\
\hline Using other drugs & $11(50 \%)$ & $11(50 \%)$ & 3.65 & $1.57-8.52$ & 3.24 & $1.04-10.13$ \\
\hline Studying in health associated faculties & $19(7.6 \%)$ & $232(92.4 \%)$ & 4.22 & $2.59-6.88$ & 2.07 & $1.05-4.10$ \\
\hline
\end{tabular}




\section{Discussion}

High prevalence of E-cigarette user in college student was found in our study. Previous reports from France [16] and United States [17] revealed $23 \%$ and $37 \%$ of college students using E-cigarette. Although the use of E-cigarette in Thailand is considered illegal, the prevalence of Ecigarette user in Thai college students was comparable to other legalized countries. This finding showed the ineffective law enforcement and E-cigarette regulation in Thailand.

We found smoking cigarette, using marijuana as risk factors of E-cigarette use. This finding was consistent with previous report from France [16], USA [17], and Taiwan [18]. The use of E-cigarette was found to be the risk factor of using marijuana [19]. By sharing same device to use both Ecigarette and marijuana, it is convenient for students to use both substances. [20-22]

Studying in health-associated faculty was a protective factor of using e-cigarette with two times less likely to use Ecigarette. This may be related to gain the knowledge in health and understand the effect of health-related problems from using E-cigarette. This finding is not consistent with previous reports [23].

Many previous reports revealed controversy regarding the efficacy of E-cigarette for smoking cessation. Systematic review and meta-analysis found that nicotine containing Ecigarette provide more efficacy for smoking cessation when compared with nicotine-free E-cigarette and nicotine replacement therapy $[24,25]$. Another report found that there was not sufficient support for E-cigarette for smoking cessation [26]. In contrast to previous reports, Kalkhoran et al found that the odds of quitting cigarette in E-cigarette user was $28 \%$ lower than those who did not use E-cigarette [27]. Our study found E -cigarette user was 25 times likely to smoke cigarette.

Previous reports found strong association of E-cigarette user and cigarette smoking [28, 29]. This research was done on the intention of resisting the pro-electronic nicotine delivery systems (ENDS) which try to create smoking norm society [30] by showing the high prevalence of E-cigarette used with risk factors in university college students. More research needs to be conducted in using of behavioral science or psychology especially in intervention that help prevent these college students from using E-cigarette.

\section{Limitation}

This study was a cross-sectional study. The causative effects of using E-cigarette may not be concluded. The population from one university was also limitation for generalization. Comorbidities, which may affect the prevalence of E cigarette user, was not included in the study. Example of comorbidities were drug addiction, sexual transmitted disease, and history of family drug use.

\section{Conclusion}

Prevalence E-cigarette users in Thai college student was high and comparable to foreign legalized countries. Risk factors of E-cigarette used were male, history of cigarette smoking, marijuana use, water pipe use and studying in nonhealth associated faculties. E -cigarette user was 25 times likely to smoke cigarette. The effective control is needed.

\section{Abbreviation \\ E-cigarette $=$ Electronic cigarette \\ GPA $=$ Grade Point Average}

\section{Declaration}

Ethic approval and consent to participate (more detail in method part ethic)

The ethic committee was thought unnecessary by our group decision due to criteria of Exemption which involved in Anonymous Observational study with minimal risk to subject.

Consent was approved by clicking YES or No in the first page of the questionnaires before start.

\section{Consent for publication}

Not applicable

\section{Availability of data and material}

The datasets generated during and/or analyzed during the current study are not publicly available due privacy of the university but are available from the corresponding author on reasonable request

\section{Competing Interests}

The authors declare that they have no competing interests.

\section{Author contribution}

All authors have read and approved the manuscript.

CS: Conceptualization, Data curation, Investigation, Methodology, Visualization, Writing original draft

JJ: Conceptualization, Data curation, Investigation, Methodology

TR: Formal analysis, Methodology

CS : Conceptualization, Resources, Validation, Supervision

TS: Project administration, Supervision, Validation, Writing - review and editing

\section{Additional}

1. Questionnaire English version: questionnaire created specifically for this study which translate from Thai 
language.

File name - Questionnaire English version

\section{References}

[1] Grana R, Benowitz N, Glantz SA. E-cigarettes: a scientific review. Circulation. 2014; 129 (19): 1972-86.

[2] King B, Patel R, Nguyen K, Dube S. Trends in Awareness and Use of Electronic Cigarettes Among US Adults, 2010-2013. Nicotine \& Tobacco Research. 2014; 17 (2): 219-227. doi: 10.1093/ntr/ntu191.

[3] Filippidis F, Laverty A, Gerovasili V, Vardavas C. Two-year trends and predictors of e-cigarette use in 27 European Union member states.

[4] Chang H, Tsai Y, Shiu M, Wang Y, Chang P. Elucidating challenges that electronic cigarettes pose to tobacco control in Asia: a population-based national survey in Taiwan. BMJ Open. 2017; 7 (3): e014263. doi: 10.1136/bmjopen-2016014263 .

[5] Sutfin E, McCoy T, Morrell H, Hoeppner B, Wolfson M. Electronic cigarette use by college students. Drug Alcohol $\begin{array}{llll}\text { Depend. } & 2013 ; & 131 & \text { (3): 214-221. doi: }\end{array}$ 10.1016/j.drugalcdep.2013.05.001.

[6] Canzan F, Finocchio E, Moretti F et al. Knowledge and use of e-cigarettes among nursing students: results from a crosssectional survey in north-eastern Italy. BMC Public Health. 2019; 19 (1). doi: 10.1186/s12889-019-7250-y.

[7] Wan Puteh S, Abdul Manap R, Maharani H et al. The use of e-cigarettes among university students in Malaygfbn sia. Tob Induc Dis. 2018; 16 (December). doi: 10.18332/tid/99539.

[8] Layden J, Ghinai I, Pray I et al. Pulmonary Illness Related to E-Cigarette Use in Illinois and Wisconsin - Preliminary Report. New England Journal of Medicine. 2019. doi: 10.1056/nejmoa1911614.

[9] Lee H, Park S, Weng M et al. E-cigarette smoke damages DNA and reduces repair activity in mouse lung, heart, and bladder as well as in human lung and bladder cells. Proceedings of the National Academy of Sciences. 2018; 115 (7): E1560-E1569. doi: 10.1073/pnas.1718185115.

[10] Grant JE, Lust K, Fridberg DJ, King AC, Chamberlain SR. Ecigarette use (vaping) is associated with illicit drug use, mental health problems, and impulsivity in university students. Ann Clin Psychiatry. 2019; 31 (1): 27-35.

[11] Rinkoo A, Kaur J. Getting real with the upcoming challenge of electronic nicotine delivery systems: The way forward for the South-East Asia region. Indian J Public Health. 2017; 61 (5): 7.

[12] Garg R, Chotbenjamaporn P, Haruhansapong V, Jumriangrit $P$, Pitayarangsarit S, Agarwal N. Tobacco use among thai students: Results from the 2015 global youth tobacco survey. Indian $J$ Public Health. 2017; 61 (5): 40. doi: 10.4103/ijph.ijph_234_17.

[13] Baiya P, Chankeaw T, Chinwong D, Chinwong S. The use of electronic cigarettes in Thailand: a cross-sectional national survey. Eur J Public Health. 2020; 30 (Supplement_5). doi: 10.1093/eurpub/ckaa166.1197.
[14] Thaitobacco.or.th. http://www.thaitobacco.or.th/th/wpcontent/uploads/2015/07/140305_ECIG-Report-

Template V28.pdf. Published 2020. Accessed January 27, 2020 .

[15] International Ethical Guidelines for Health-related Research Involving Humans, Fourth Edition. Geneva. Council for International Organizations of Medical Sciences (CIOMS); 2016.

[16] Tavolacci, M., Vasiliu, A., Romo, L., Kotbagi, G., Kern, L., \& Ladner, J. (2016). Patterns of electronic cigarette use in current and ever users among college students in France: a cross-sectional study. BMJ Open, 6 (5), e 011344. doi: 10.1136/bmjopen-2016-011344.

[17] Copeland A, Peltier M, Waldo K. Perceived risk and benefits of e-cigarette use among college students. Addict Behav. 2017; 71: 31-37. doi: 10.1016/j.addbeh.2017.02.005.

[18] Lee Y, Chang L, Hsu C, Chen P. Comparing the Characteristics of Cigarette Smoking and e-Cigarette and IQOS Use among Adolescents in Taiwan. J Environ Public Health. 2020; 1-8. doi: 10.1155/2020/7391587.

[19] Chadi N, Schroeder R, Jensen J, Levy S. Association Between Electronic Cigarette Use and Marijuana Use Among Adolescents and Young Adults. JAMA Pediatr. 2019; 173 (10): e192574. doi: 10.1001/jamapediatrics.2019.2574.

[20] Morean M, Kong G, Camenga D, Cavallo D, Krishnan-Sarin S. High School Students' Use of Electronic Cigarettes to Vaporize Cannabis. Pediatrics. 2015; 136 (4): 611-616. doi: 10.1542/peds.2015-1727.

[21] Morean M, Lipshie N, Josephson M, Foster D. Predictors of Adult E-Cigarette Users Vaporizing Cannabis Using ECigarettes and Vape-Pens. Subst Use Misuse. 2017; 52 (8): 974-981. doi: 10.1080/10826084.2016.1268162.

[22] Lozano P, Barrientos-Gutierrez I, Arillo-Santillan E et al. A longitudinal study of electronic cigarette use and onset of conventional cigarette smoking and marijuana use among Mexican adolescents. Drug Alcohol Depend. 2017; 180: 427430. doi: 10.1016/j.drugalcdep.2017.09.001.

[23] Franks A, Hawes W, McCain K, Payakachat N. Electronic cigarette use, knowledge, and perceptions among health professional students. Currents in Pharmacy Teaching and Learning. $\quad 2017 ; \quad 9 \quad$ (6): 1003-1009. doi: 10.1016/j.cptl.2017.07.023.

[24] Hartmann-Boyce J, McRobbie H, Lindson N et al. Electronic cigarettes for smoking cessation. Cochrane Database of Systematic Reviews. $2020 . \quad$ doi: 10.1002/14651858.cd010216.pub4.

[25] Villalobos R, Ambrocio G, Fernandez L. Electronic cigarettes for smoking cessation: an individual patient meta-analysis of randomized controlled trials. Tobacco, smoking control and health educ. 2019. doi: 10.1183/13993003.congress2019.oa5135.

[26] Banks E, Yazidjoglou A, Brown S et al. Systematic review and meta-analysis of evidence on the efficacy of e-cigarette use for sustained smoking and nicotine cessation. 2020. doi: $10.1101 / 2020.11 .02 .20224212$.

[27] Kalkhoran S, Glantz S. E-cigarettes and smoking cessation in real-world and clinical settings: a systematic review and metaanalysis. The Lancet Respiratory Medicine. 2016; 4 (2): 116128. doi: 10.1016/s2213-2600(15)00521-4. 
[28] Soneji S, Barrington-Trimis J, Wills T et al. Association Between Initial Use of e-Cigarettes and Subsequent Cigarette Smoking Among Adolescents and Young Adults. JAMA

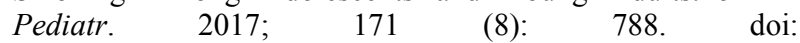
10.1001/jamapediatrics.2017.148830.

[29] Sawdey M, Day H, Coleman B et al. Associations of risk factors of e-cigarette and cigarette use and susceptibility to use among baseline PATH study youth participants (2013-2014). Addict Behav. 2019; 91: 51-60. doi: 10.1016/j.addbeh.2018.11.027.

[30] Patanavanich R, Glantz S. Successful countering of tobacco industry efforts to overturn Thailand's ENDS ban. Tob Control. 2020: tobaccocontrol-2020-056058. doi: 10.1136/tobaccocontrol-2020-056058. 